\title{
Arg-Leu-Tyr-Glu tetrapeptide inhibits tumor progression by suppressing angiogenesis and vascular permeability via VEGF receptor-2 antagonism
}

\author{
Yi-Yong Baek ${ }^{1, *}$, Dong-Keon Lee ${ }^{1, *}$, Joohwan Kim¹, Ji-Hee Kim¹, Wonjin Park ${ }^{1}$, \\ Taesam Kim¹, Sanghwa Han², Dooil Jeoung, ${ }^{2}$, Ji Chang You ${ }^{3}$, Hansoo Lee ${ }^{4}$, Moo-Ho \\ Won ${ }^{5}$, Kwon-Soo Ha ${ }^{1}$, Young-Guen Kwon ${ }^{6}$, Young-Myeong Kim ${ }^{1}$ \\ ${ }^{1}$ Department of Molecular and Cellular Biochemistry, School of Medicine, Kangwon National University, Chuncheon, Gangwon- \\ do, 200-702, South Korea \\ ${ }^{2}$ Department of Biochemistry, College of Natural Sciences, Kangwon National University, Chuncheon, Gangwon-do, 200-702, \\ South Korea \\ ${ }^{3}$ Department of Pathology, School of Medicine, The Catholic University of Korea, Seoul 137-701, Korea \\ ${ }^{4}$ Department of and Life Sciences, College of Natural Sciences, Kangwon National University, Chuncheon, Gangwon-do, 200- \\ 702, South Korea \\ ${ }^{5}$ Department of Neurobiology, School of Medicine, Kangwon National University, Chuncheon, Gangwon-do, 200-702, South \\ Korea \\ ${ }^{6}$ Department of Biochemistry, College of Life Science and Biotechnology, Yonsei University, Seoul, 120-752, South Korea \\ "These authors have contributed equally to this work \\ Correspondence to: Young-Myeong Kim, email: ymkim@kangwon.ac.kr \\ Keywords: antiangiogenic peptide, tumor growth and metastasis, VEGFR-2, VEGF-A \\ Received: December 21,2015 Accepted: December 03, $2016 \quad$ Published: December 28, 2016
}

\section{ABSTRACT}

The tetrapeptide Arg-Leu-Tyr-Glu (RLYE) is known to inhibit vascular endothelial growth factor-A (VEGF-A)-induced angiogenesis in vitro. Herein, we examined its underlying mechanism and antitumor activity associated with vascular remodeling. RLYE inhibited VEGF-A-induced angiogenesis in a mouse model and suppressed VEGF-A-induced angiogenic signal cascades in human endothelial cells. However, RLYE showed no inhibitory effect on VEGF-A-induced proliferation and migration of multiple myeloma cells expressing VEGF receptor (VEGFR)-1, but not VEGFR-2. In addition, RLYE showed no inhibitory effect on angiogenic activities induced by VEGF-B, basic fibroblast growth factor, epithermal growth factor, sphingosine1-phosphate, and placental growth factor. RLYE bound specifically to VEGFR-2 at the VEGF-A binding site, thereby blocking VEGF-A-VEGFR-2 binding and VEGFA-induced VEGFR-2 internalization. The RLYE peptide inhibited tumor growth and metastasis via suppression of tumor angiogenesis in tumor-bearing mice. Moreover, RLYE showed a synergistic effect of the cytotoxic agent irinotecan on tumor cell apoptosis and tumor progression via tumor vessel normalization due to stabilization of VE-cadherin-mediated adherens junction, improvement of pericyte coverage, and inhibition of vascular leakage in tumors. Our results suggest that RLYE can be used as an antiangiogenic and tumor blood vessel remodeling agent for inhibition of tumor growth and metastasis by antagonizing VEGFR-2, with the synergistic anti-cancer effect via enhancement of drug delivery and therapeutic efficacy.

\section{INTRODUCTION}

Robust tumor growth results in hypoxia, which promotes the stabilization of the oxygen-sensitive transcription factor hypoxia-inducible factor-1alpha (HIF-1 $\alpha$ ) that induces the expression of multiple genes implicated in angiogenesis, metabolism, and cell survival $[1,2]$. Of the prominent gene products, vascular 
endothelial growth factor (VEGF) strongly stimulates the formation of new blood vessels (angiogenesis) and vascular networks that supply both nutrients and oxygen to tumor cells, resulting in tumor growth and invasion as well as metastasis $[3,4]$. Thus, antiangiogenic treatment that targets the VEGF/VEGF receptor (VEGFR) pathway is a potential strategy to inhibit tumor vessel growth, thus abrogating tumor progression and metastasis.

Several studies have focused on the development of humanized monoclonal antibodies and small molecules that inhibit tumor angiogenesis by targeting the tumorassociated endothelial cells [5-7]. Angiogenesis inhibitors including neutralizing VEGF antibodies and receptor-tyrosine kinase inhibitors, such as bevacizumab, ramucirumab, sunitinib, and axitinib, have been developed and used clinically to treat several solid tumors including colorectal cancer and renal cell carcinoma [8]. Recently, they reduce tumor blood vessel abnormalities (that are, vascular junction destabilization, pericyte loss, and vascular permeability and leakage) and improve delivery of anticancer drugs to tumor, thereby potentiating efficacy of their antitumor activity [9, 10]. However, the antiVEGF antibody bevacizumab has some limitations due to adverse effects of arterial hypertension, arterial and venous thrombosis, cardiovascular events, and gastrointestinal bleeding [11]. In addition, small chemical drugs that inhibit VEGF receptor tyrosine kinase can also suppress several other tyrosine kinase activities due to low specificity, thus resulting in unwanted side effects, such as hypertension or proteinuria $[12,13]$.

Specific inhibitors targeting VEGFR-2, a primary receptor for VEGF family members driving angiogenesis, are needed for inhibition of tumor angiogenesis and vessel leakage. Ramucirumab is a fully humanized monoclonal antibody bound to the extracellular domain of VEGFR-2. Ramucirumab treatment of various malignancies has shown promising clinical antitumor efficacy and tolerability. Although ramucirumab has been suggested to elicit hypertension as an adverse event [14], it can be manageable [15]. Thus, VEGFR-2 is a promising target for treatment of cancer patients.

Angiostatin, a potent inhibitor of angiogenesis, was first identified as an endogenous kringle (domains 1-4)-containing fragment produced from plasminogen, which selectively inhibits endothelial cell proliferation [16]. Thereafter, a single kringle 5 of plasminogen was shown to be more effective in anti-endothelial cell proliferation than angiostatin [17], and the tetrapeptide Lys-Leu-Tyr-Asp (KLYD) derived from the kringle 5 was revealed to have a potent inhibitory effect on endothelial cell proliferation [18]. We recently demonstrated that ArgLeu-Tyr-Glu (RLYE) can more effectively inhibit VEGFinduced angiogenic activity in vitro than KLYD [19]. However, its underlying mechanism of action is unclear, as are the pharmacological effects on tumor angiogenesis, tumor blood vessel leakage, and tumor progression in an animal model.
In this study, we examined the therapeutic effects of RLYE on tumor progression and its molecular target for antiangiogenic therapy. RLYE inhibited VEGF-A-induced angiogenesis in vivo by directly binding to VEGFR-2, but not VEGFR-1, and subsequently blocked the interaction between VEGF-A and VEGFR-2 and its downstream signaling cascades. Thus, the peptide inhibited tumor growth and metastasis by suppressing tumor angiogenesis. In addition, RLYE potentiated the synergistic effect of the cytotoxic agent irinotecan on tumor cell apoptosis and tumor growth inhibition, probably by increasing drug delivery to tumor, via reduction of tumor vessel abnormality due to restoration of endothelial adherens junction and pericyte coverage. These findings demonstrate that RLYE is a potent antiangiogenic and vascular remodeling drug that binds to VEGFR-2, thus providing a new therapeutic strategy for solid tumors.

\section{RESULTS}

\section{RLYE inhibits angiogenesis ex vivo and in vivo}

Since RLYE inhibits in vitro angiogenic behaviors, such as proliferation, migration, and tube-like structure formation, of HUVECs treated with VEGF-A [19], we hypothesize that RLYE can inhibit tumor growth and metastasis via inhibition of tumor angiogenesis. To confirm this hypothesis, we first examined the effects of RLYE on angiogenesis ex vivo and in vivo. In an ex vivo angiogenesis assay using explanted rat aortic rings in Matrigel matrices, RLYE significantly inhibited vessel sprouting in the cut edge of aortic rings exposed to VEGF-A (Figure 1A). In addition, similar results were also obtained in mouse aortic ring sprouting assay (Supplementary Figure 1). We also investigated whether RLYE is capable of regulating in vivo angiogenesis using the chick chorioallantoic membrane (CAM) assay. RLYE treatment markedly suppressed the total surface density of capillaries induced by VEGF-A (Figure 1B). However, the peptide RLME that has no antiangiogenic activity [19] did not inhibit VEGF-induced angiogenesis in the CAM model (Figure 1B). We further confirmed the antiangiogenic capability of RLYE in an animal model using intravital microscopy. Treatment with RLYE effectively blocked VEGF-A-induced increases in the angiogenic characteristics of capillary sprouting and neovessel formation (Figure 1C). These results indicate that RLYE is capable of inhibiting VEGF-A-induced neovessel formation in vivo.

\section{RLYE blocks VEGF-induced angiogenic signaling by inhibiting VEGFR-2 activation}

To understand the molecular mechanism by which RLYE inhibits VEGF-induced angiogenesis, we examined the effect of RLYE on intracellular signaling events triggered by VEGF-A. Treatment of HUVECs with RLYE inhibited several angiogenic signals, such as 
the cell proliferation signals p38 and ERK activation, the cell migration signals Src and FAK phosphorylation, and the cell survival signal Akt phosphorylation, in HUVECs stimulated with VEGF-A (Figure 2A-2C). In addition, RLYE effectively blocked VEGF-A-induced endothelial nitric oxide synthase (eNOS) phosphorylation and NO production (Figure 2C-2E), which improve endothelial and vascular function [20] Furthermore, RLYE inhibited the apical angiogenic signal event VEGFR-2 phosphorylation in HUVECs treated with VEGF-A (Figure 2F). These results suggest that RLYE inhibits VEGF-A-induced signal cascades by inhibiting VEGFR-2 phosphorylation.

\section{RLYE does not inhibit angiogenesis induced by basic fibroblast growth factor (bFGF), epidermal growth factor (EGF), and sphingosine 1-phosphate (S1P)}

We next investigated whether RLYE inhibits angiogenesis induced by other angiogenic factors, such as bFGF, EGF and S1P. Treatment of RLYE did not inhibit bFGF-induced increases in human endothelial cell migration and tube formation, while this peptide effectively suppressed VEGF-A-induced angiogenesis (Figure $3 \mathrm{~A}$ and $3 \mathrm{~B}$ ). In addition, RLYE did not inhibit EGF-induced endothelial cell migration (Figure 3C). Since the bioactive lipid S1P stimulates endothelial cells to promote angiogenesis [21], we next examined the regulatory effect of RLYE on S1P-induced angiogenesis. S1P strongly increased endothelial cell migration, and this effect was not inhibited by RLYE (Figure 3D). However, the peptide did not induce any cytotoxicity against HUVECs (Supplementary Figure 2A). These findings suggest that RLYE inhibits angiogenesis induced by VEGF-A, but not by other angiogenic factors including bFGF, EGF, and S1P.

\section{RLYE inhibits angiogenesis induced by VEGFR-2, but not VEGFR-1}

Since VEGF-A activates both VEGFR-1 and VEGFR-2 that are expressed in endothelial cells [22], we investigated whether RLYE inhibited one or both of these receptors. We first examined the effects of RLYE on proliferation and migration of two multiple myeloma (MM) cell lines, IM-9 and RPMI 8226 cells, which express VEGFR-1, but not VEGFR-2 [23, 24]. Interestingly, RLYE did not suppress VEGF-A-induced proliferation and migration of both cell lines (Figure $4 \mathrm{~A}$ and 4B). We next examined the effect of RLYE on migration of HUVECs stimulated with VEGF-A (ligand for VEGFR-1/2), placental growth factor (PlGF, a ligand for VEGFR-1), and VEGF-B (ligand for VEGFR-1). RLYE markedly inhibited endothelial cell migration elicited by VEGF-A, but not PlGF and VEGF-B (Figure 4C). As expected, similar inhibitory effects of RLYE
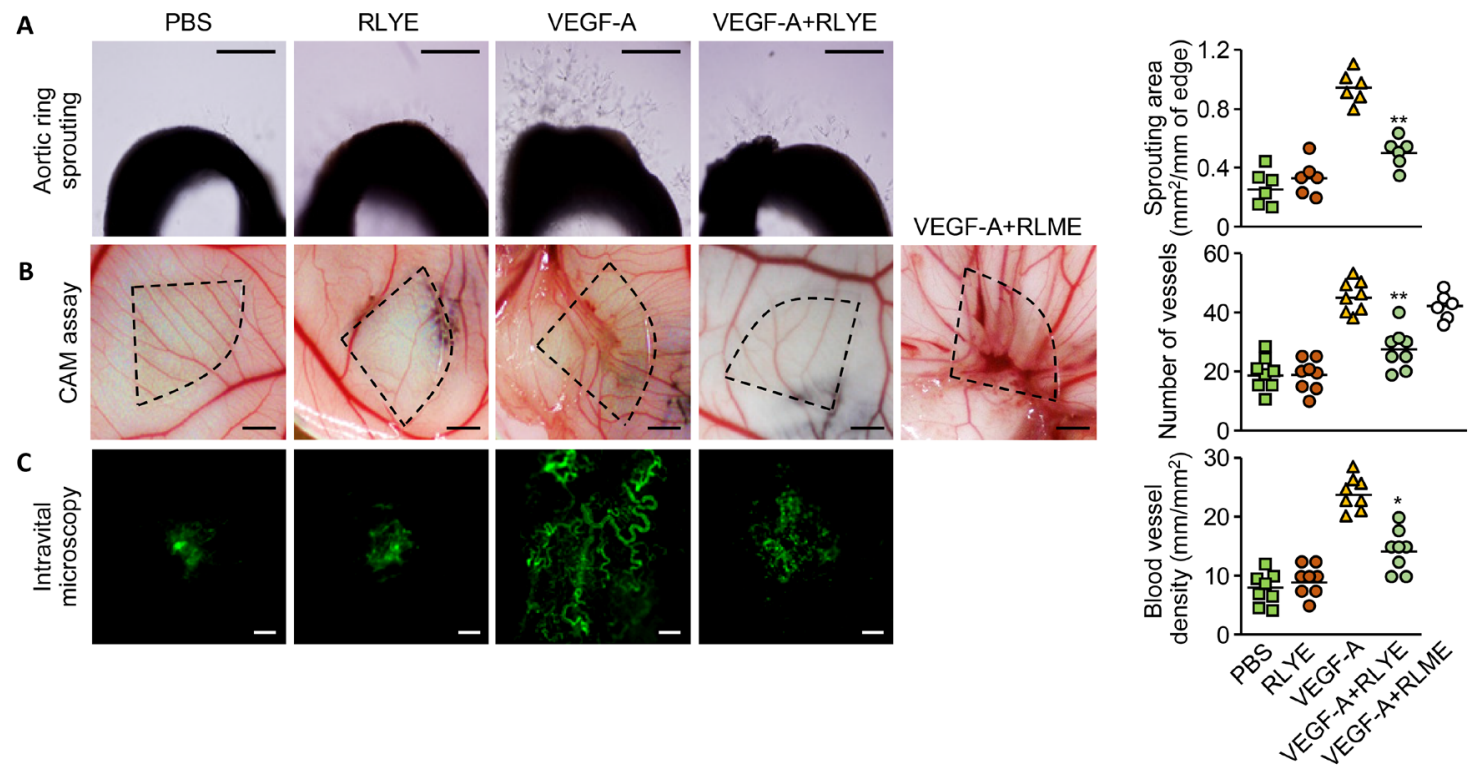

Figure 1. RLYE inhibits angiogenesis ex vivo and in vivo. A. Rat aortic rings were incubated with VEGF-A, RLYE or combined together. On day 6, newly formed vessels were fixed and microvessel outgrowth was photographed under a phase contrast microscope. Scale bar, $200 \mu \mathrm{m}$. B. Thermanox discs containing VEGF-A, RLYE, VEGF-A plus RLYE or VEGF-A plus RLME were loaded onto the CAM of 10-day-old embryos. After $72 \mathrm{~h}$ incubation, the area around the loaded disc was photographed. Scale bar, $2 \mathrm{~mm}$ C. Matrigel containing VEGF-A alone or in combination with RLYE was applied to the inner space of window, which was surgically implanted between the skin and abdominal wall of mice. After 4 days, neovascularization was recorded using a fluorescence microscope after intravenous injection of FITC-labeled dextran. Angiogenesis was assessed as described in the Methods section. Scale bar, $200 \mu \mathrm{m}$. Data are the mean \pm $\mathrm{SD}(\mathrm{n} \geq 6) . * P<0.05$ and $* * P<0.01$ versus VEGF-A alone. 


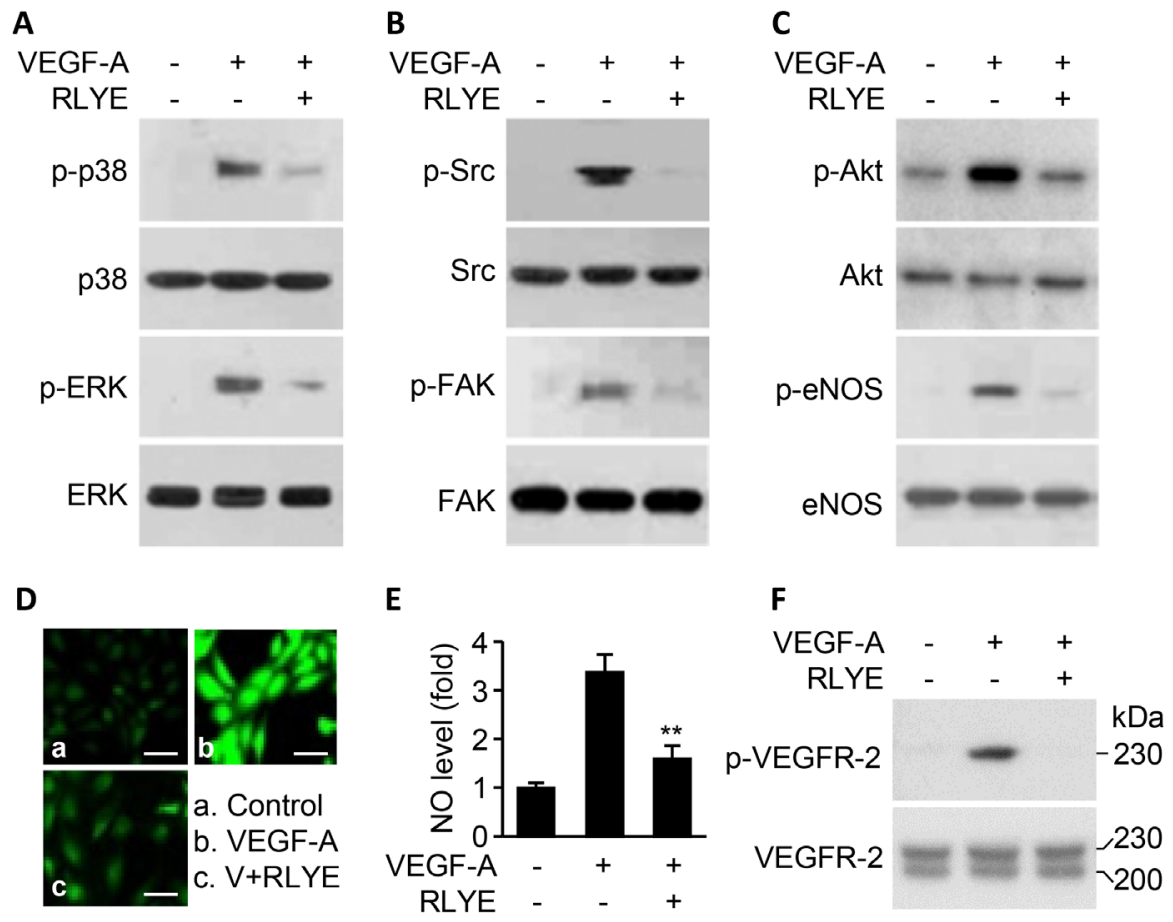

Figure 2: RLYE inhibits VEGF-A-induced angiogenic signal cascades. HUVECs were treated with VEGF-A (10 ng/ml) alone or in combination with RLYE $(0.15 \mathrm{nM})$ for $30 \mathrm{~min}$, except for measurement of NO in cells that were incubated for $4 \mathrm{~h}$. Cell lysates were separated by SDS-PAGE, followed by Western blotting to determine the phosphorylation levels of p38MAPK and ERK A. Src and FAK B. Akt and eNOS C. and VEGFR-2 (F). D and E. The levels of intracellular NO were determined by confocal microscopy using DAF-FM. Scale bar, $50 \mu \mathrm{m}$. F. Two VEGFR-2 bands with MW of 220 and $230 \mathrm{kDa}$ indicate intermediate and mature forms, respectively. Data are the mean $\pm \mathrm{SD}(\mathrm{n}=6) . * * P<0.01$ versus VEGF-A alone.

A
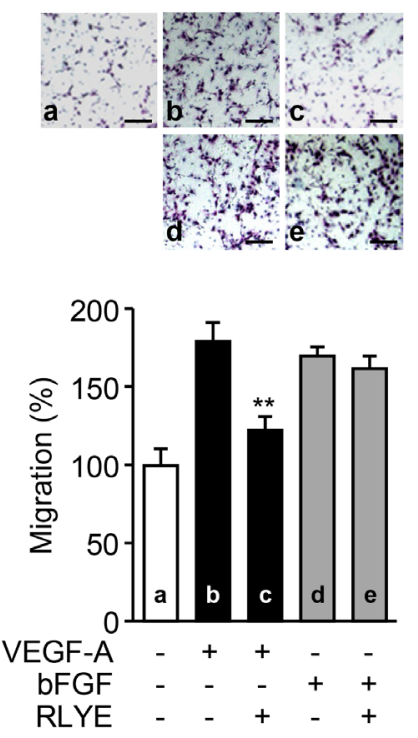

B
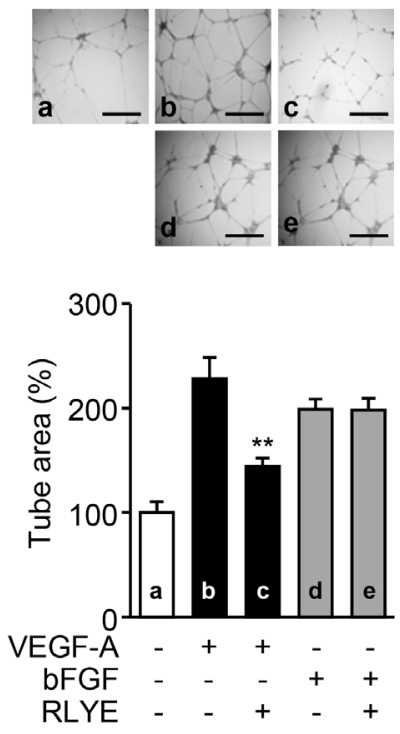
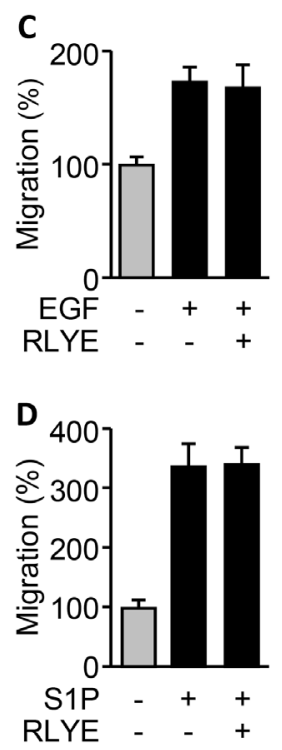

Figure 3: RLYE inhibits in vitro angiogenesis induced by VEGF-A, but not bFGF, EGF, and S1P. HUVECs were incubated with VEGF-A $(10 \mathrm{ng} / \mathrm{ml})$, bFGF $(10 \mathrm{ng} / \mathrm{ml})$, EGF $(20 \mathrm{ng} / \mathrm{ml})$ or S1P $(1 \mathrm{nM})$ in the presence or absence of RLYE $(0.15 \mathrm{nM})$. A. Endothelial cell migration was determined by the Boyden chamber assay. Cells that migrated to the lower side of the filter were counted. Scale bar, 100 $\mu \mathrm{m}$. B. Images of tube-like structure were photographed using an inverted phase contrast microscope, and the tube length was quantified using Image-Pro Plus software. Scale bar, $500 \mu \mathrm{m}$. C and D. Endothelial cell migration was determined by Boyden chamber assay. Data are the mean $\pm \mathrm{SD}(\mathrm{n}=3)$. $* * P<0.01$ versus VEGF alone. 
on the angiogenic signal ERK activation were observed in HUVECs stimulated with VEGFR-1 and VEGFR-2 ligands (Figure 4D). These results suggest that RLYE inhibits angiogenic phenomena induced by VEGFR-2, but not VEGFR-1.

\section{RLYE interacts with VEGFR-2, but not VEGFR-1}

We next investigated whether RLYE binds to VEGFR-2 in endothelial cells. HUVECs were incubated with FITC-conjugated RLYE before or after VEGF-A treatment, and FACS was performed to determine the binding capacity of RLYE to endothelial cells. RLYE bound to the surface of control HUVECs, and this binding was blocked by pre-, but not post-, incubation of endothelial cells with VEGF-A (Figure 5A and 5B). In addition, RLYE binding was colocalized with the endothelial cell marker CD31 (PECAM-1) or VEcadherin. Moreover, a pull-down assay showed that RLYE bound to VEGFR-2, but not VEGFR-1, expressed in HUVECs (Figure 5C and 5D). Under similar experimental condition, confocal analysis showed that RLYE bound to the surface of HUVECs, and this binding was effectively blocked by pretreatment with VEGF-A (Figure 5E). Since the surface VEGFR-2 of endothelial cells undergoes internalization (to the nucleus) by VEGF ligation [25], we further examined whether RLYE inhibits nuclear translocation of VEGFR-2 in HUVECs stimulated with VEGF-A. VEGF-A treatment increased nuclear level of VEGFR-2, accompanied by a decrease in membrane and cytosolic VEGFR-2 level, while RLYE did not affect VEGF localization (Supplementary Figure 3). Interestingly, pretreatment with RLYE impaired VEGFA-induced internalization of VEGFR-1, and RLYE posttreatment inhibited partially VEGF-A-induced nuclear localization of VEGFR-2 (Supplementary Figure 3). These results suggest that RLYE impaired VEGFR-2 internalization by binding to the receptor and then blocking VEGF-A ligation.

\section{An in silico modeling of RLYE binding to VEGFR-2}

To investigate the possible interaction of RLYE with VEGFR-2, a docking analysis was performed. Blind docking of RLYE to VEGFR-2 produced a tightly bound conformation with a small dissociation constant (194 nM). Interestingly, RLYE bound to VEGFR-2 at the interface between immunoglobulinhomology domains D2 and D3 (Figure 6A), which is known to be the binding site for VEGF-A/C [26]. Charged residues at both termini of the peptide bind to hydrophilic pockets, while other noncharged residues were placed close to hydrophobic patch
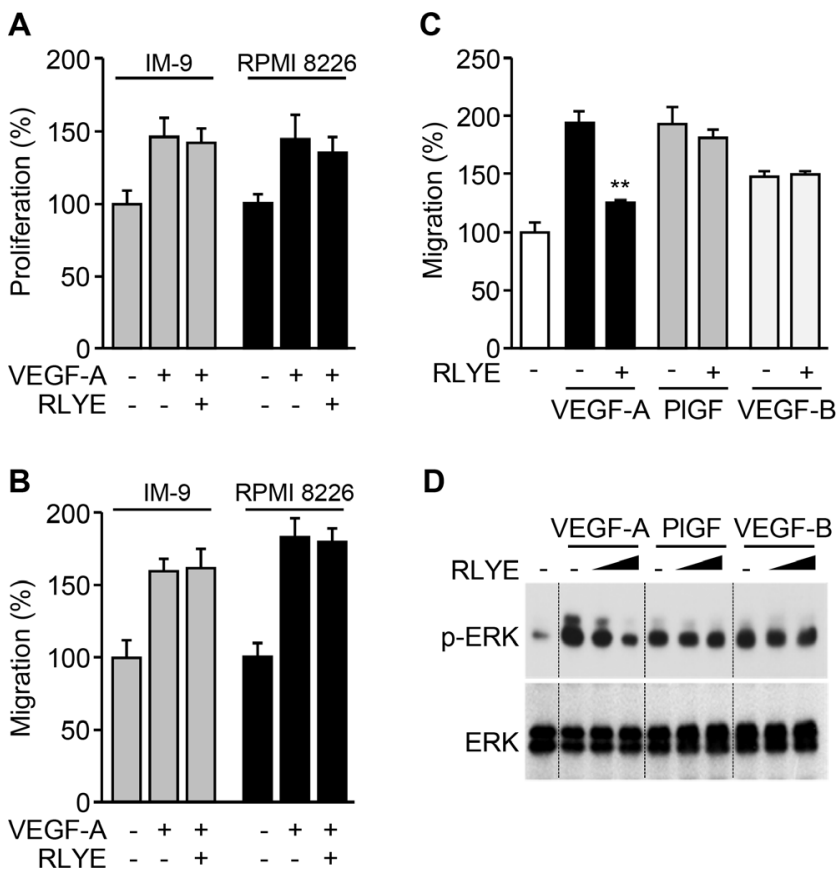

D

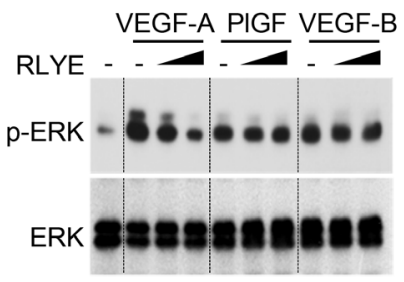

Figure 4: RLYE inhibits in vitro angiogenic events induced by VEGFR-2, but not VEGFR-1. A. and B. IM-9 and RPMI 8226 cells were incubated VEGF-A alone or in combination with RLYE. (A) Cell proliferation was determined by $\left[{ }^{3} \mathrm{H}\right]$-thymidine incorporation assay. (B) Endothelial cell migration was determined by Boyden chamber assay. C and D. HUVECs were incubated with VEGF-A (10 ng/ $\mathrm{ml})$, PlGF (20 ng/ml) or VEGF-B (20 ng/ml) in the presence or absence of RLYE $(0.15 \mathrm{nM})$. (C) Endothelial cell migration was determined in a Boyden chamber. (D) ERK phosphorylation was determined by Western blotting. Data are the means $\pm \operatorname{SD}(\mathrm{n}=3)$. $* * P<0.01$ versus VEGF-A alone. 
A

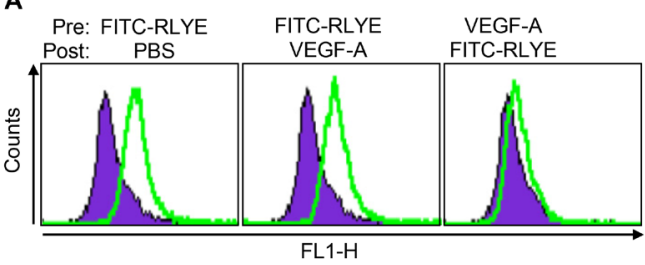

B

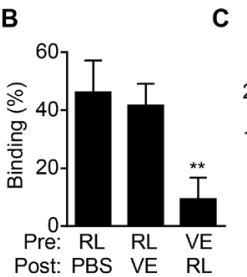

C
E

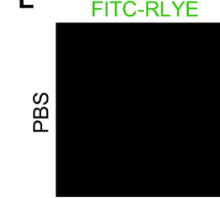

CD31

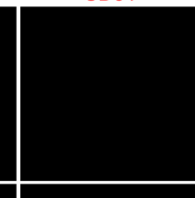

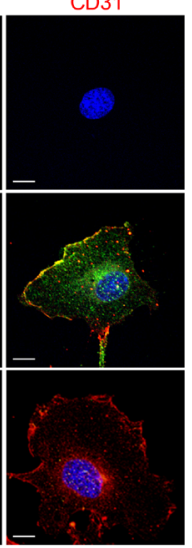

FITC-RLYE +

VE-Cadherin

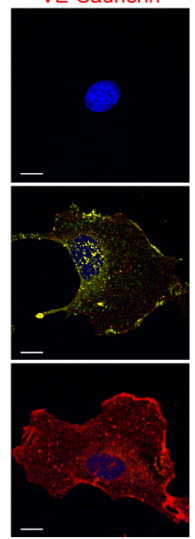

Figure 5: RLYE binds to endothelial cells through binding to VEGFR-2. A and B. HUVECs were incubated with FITCconjugated RLYE (RL, $15 \mathrm{nM}$ ) before or after treatment with VEGF-A (VE, $100 \mathrm{ng}$ ) for $30 \mathrm{~min}$. Cells were analyzed by flow cytometry (A) and quantified (B). Data are the means $\pm \mathrm{SD}(\mathrm{n}=5)$. ${ }^{*} P<0.01$ versus RLYE alone. $\mathbf{C}$ and D. HUVEC lysates were incubated with biotinylated RLYE (Bio-RLYE, 0.15 or $1.5 \mathrm{nM}$ ), followed by precipitation with streptavidin-agarose beads. The red arrow indicates VEGFR-2 protein bands on a longer exposure film. The precipitates were separated by SDS-PAGE. VEGFR-2 or VEGFR-1 expression was assessed by Western blot analysis. E. HUVECs were treated with or without VEGF-A $(10 \mathrm{ng} / \mathrm{ml})$ for 30 min, followed by incubation with FITC-conjugated RLYE (100 ng/ml, green). Cells were incubated with a TRITC-conjugated CD31 antibody (1:100, red) or DAPI (blue). Confocal microscopy was performed for analyzing binding of RLYE on HUVECs. Scale bar, $10 \mu \mathrm{m}$.

A

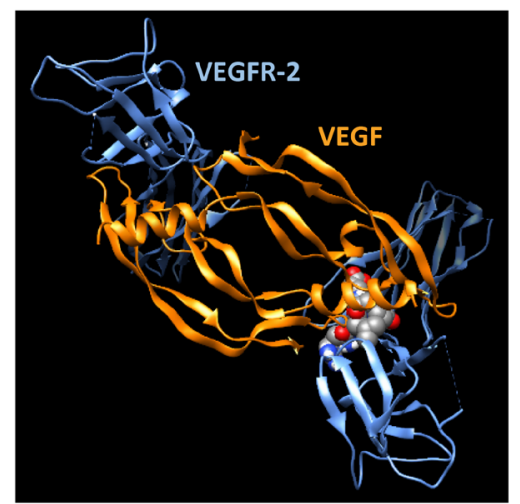

C

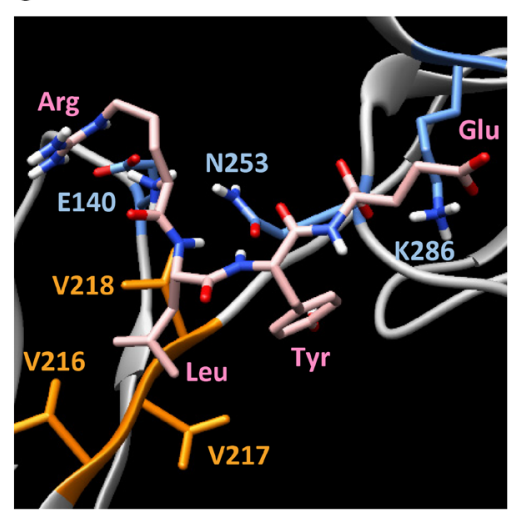

B

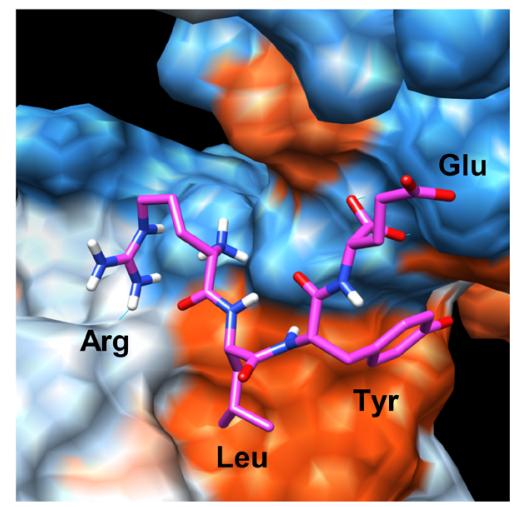

D

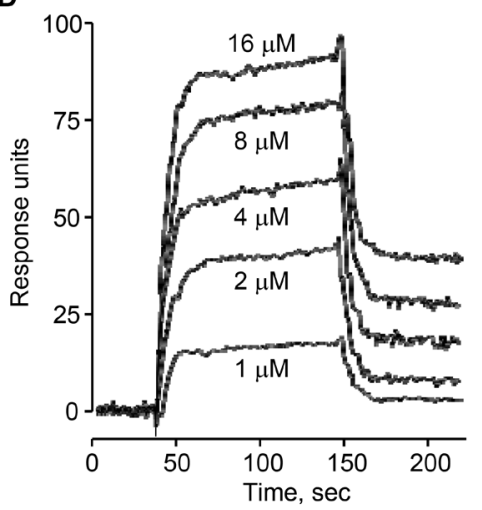

Figure 6: Binding of RLYE to VEGFR-2. A. In silico molecular docking structure of the RLYE peptide (red spheres) bound at the interface between VEGFR-2 (blue) and VEGF (orange). B. Binding model of RLYE to VEGFR-2. Red and blue colors represent hydrophobic and hydrophilic regions, respectively. C. Interaction of the RLYE peptide (pink) with VEGFR-2. The residues E140, N253, and K286 (blue) of VEGFR-2 are involved in electrostatic interaction and hydrogen bonding with Arg and Glu of the RLYE peptide whereas Val residues (orange) participate in hydrophobic interaction Leu of the peptide. D. SPR analysis was performed for determining the interaction between RLYE and rhVEGFR-2. 
(Figure 6B). The terminal Arg and Glu residues of the peptide bind electrostatically to Glu140 and Lys286 of VEGFR-2, respectively, whose Lys286 is known to form a salt bridge with Glu64 of VEGF-A (Figure 6C) [26]. The Arg residue also formed a hydrogen bond with Asn253 of VEGFR-2, which is critically involved in interaction with VEGF-A [26]. The Leu side chain contacted a hydrophobic region comprised of Val216-218 of VEGFR-2, which elicit a hydrophobic interaction with VEGF-A [26], thus favoring hydrophobic interaction between RLYE and VEGFR-2. On the other hand, the aromatic ring of Tyr also interacted hydrophobically with Val216-218 residues of VEGFR-2, while its hydroxyl group formed a hydrogen bond with the amide carbonyl of Asn253. These results suggest that RLYE binds to VEGFR-2 at the same binding site of VEGF-A. Next, the binding between RLYE and rhVEGFR-2 was demonstrated by SPR analysis. The sensorgrams displayed saturable binding behavior of RLYE to rhVEGFR-2, and Kd of RLYE binding to VEGFR-2 was calculated as $9.0 \mu \mathrm{M}$ (Figure 6D). These results suggest that RLYE sterically blocks the ligand VEGF-A binding by interaction with VEGFR-2 and potentially inhibits VEGF-A-induced angiogenesis.

\section{RLYE inhibits growth and metastasis of mouse melanoma tumors in a mouse model}

Since VEGFR-2 is critically involved in tumor angiogenesis [18], we next evaluated the pharmacological effects of RLYE on tumor progression in a mouse model. B16F1 melanoma cells were injected s.c. into the flanks of mice, and tumor-bearing mice were injected i.p. with RLYE at a dose of $1 \mathrm{mg} / \mathrm{kg} /$ day. Treatment with RLYE resulted in a significant decrease of tumor size, weight, and growth (Figure 7A-7C). To explore the inhibitory effect of RLYE on tumor metastasis in vivo, mice were injected with B16F10 melanoma cells into the tail vein and injected i,p. with RLYE at a dose of $1 \mathrm{mg} / \mathrm{kg} / \mathrm{day}$. Three weeks later, metastatic colonies were analyzed in the lungs. Administration with RLYE resulted in a $62 \%$ reduction in number of metastatic colonies in the lungs compared with untreated control mice (Figure 7D and 7E). These results suggest that RLYE is capable of inhibiting tumor growth and metastasis.

\section{RLYE inhibits human xenograft tumor growth via antiangiogenic action}

To investigate the effect of RLYE on human tumor growth and tumor angiogenesis in a xenograft mouse model, nude mice bearing subcutaneous human colorectal tumor (HCT116) xenograft were injected i.p. with 0.5 or $1.0 \mathrm{mg} / \mathrm{kg}$ every day. Treatment with RLYE significantly decreased the tumor size and inhibited tumor growth in a concentration-dependent manner (Figure 7F and 7G), while the peptide showed no cytotoxic effect on cultured
HCT116 cells up to $30 \mathrm{nM}$, which is relatively equal to the blood concentration of mice ( $22 \mathrm{~g}$ of body weight) injected with $1 \mathrm{mg} / \mathrm{kg}$ (Supplementary Figure 2B). Hemoglobin concentration in tumor tissues was determined to assess functional angiogenesis [27]. RLYE-treated tumors had a reduction in $41 \%$ hemoglobin content compared to control tumors (Figure $7 \mathrm{H}$ ). Immunohistochemistry of tumor tissues showed that RLYE treatment resulted in dose-dependent decrease in staining with FITC-isolectin B4 and an anti-CD31 (PECAM-1) antibody (Figure 7I), indicating that the peptide inhibits tumor angiogenesis. The inhibitory effects of RLYE on tumor growth and angiogenesis were relatively little lower than those of bevacizumab (2 mg/kg, twice per week) as a positive control. These results suggest that the antitumor efficacy of RLYE is closely correlated with its antiangiogenic effect in a xenograft mouse model.

\section{RLYE inhibits vascular leakage and enhances tumor chemosensitivity}

VEGF has a prominent role in leakiness of tumor blood vessels, hence, we first investigated the effect of RLYE on VEGF-induced endothelial cell permeability in cultured HUVECs. RLYE significantly attenuated VEGF-induced sucrose permeability in endothelial cell monolayers (Figure 8A). RLYE also inhibited VEGF-induced phosphorylation of VE-cadherin, an adherens junction protein, resulting in prevention of VEGF-mediated VE-cadherin loss from endothelial adherent junctions (Figure $8 \mathrm{~B}$ and $8 \mathrm{C}$ ). The results suggest that RLYE attenuates VEGF-induced endothelial permeability by blocking VEGFR-2. In addition, the Evans blue method in HCT116 tumor-bearing nude mice demonstrated that RLYE reduced tumor blood vessels leakage (Figure 8D). Similar effect of RLYE on blood vessel leakage was observed in the human tumor xenograft model by FITC-dextran image assay (Figure $8 \mathrm{E}$ and $8 \mathrm{~F}$ ). These data suggest that RLYE inhibits tumor vessel hyperpermeability, which is largely regulated by endothelial cell junction and pericyte coverage [9]. We next examined the effect of RLYE on endothelial cellcell junction and pericyte coverage of tumor vessels, an indicator of vascular stabilization and functionality. RLYE increased the numbers of VE-cadherin-positive vessels (Figure 8G and 8H) and the pericyte marker NG2-positive vessels in HCT116 tumors (Figure 8I and 8J). Reducing vascular leakage enhances drug delivery to tumor and chemotherapeutic efficacy $[9,10]$. Therefore, we evaluated the therapeutic effect of co-treatment with RLYE and the anticancer drug irinotecan (camptothecin-II, CPT-11) on tumor progression in a mouse model. Treatment with the peptide or CPT-11 alone significantly inhibited tumor growth in mice bearing HCT116 colon tumor. The growth inhibition was further augmented in the group treated with combination of RLYE and CPT-11 (Figure 8K). 
TUNEL-positive apoptotic cells were markedly increased in tumor tissues of the combination treatment group, as compared with the monotherapy groups (Figure 8L and $8 \mathrm{M})$. These results suggest that RLYE reduces tumor blood vessel permeability and leakage via promotion of endothelial junction stability and pericyte coverage, leading to enhanced anticancer drug delivery to tumor and therapeutic efficacy.

\section{DISCUSSION}

Since angiogenesis is necessary for tumor progression and metastasis, angiogenesis inhibitors are a clinically validated anticancer drug. In the present study, we examined the antiangiogenic mechanism of the tetrapeptide RLYE and its therapeutic effect on tumor growth and metastasis. The peptide suppressed angiogenic activity of VEGF-A, but not of VEGF-B, bFGF, PIGF, and S1P, by directly binding to VEGFR-2, but not VEGFR-1, in human endothelial cells. Furthermore, RLYE showed antitumor activity in both $\mathrm{C} 57 \mathrm{BL} / 6 \mathrm{~J}$ mice bearing melanoma B16F10 tumors and athymic nude mice bearing colorectal HCT116 tumors, as well as suppressed lung metastasis of B16F1 melanoma in a mouse model. This peptide also inhibited tumor angiogenesis in a mouse xenograft model of colorectal cancer. These findings suggest that RLYE possesses strong therapeutic potential for solid tumors via antiangiogenic action.

Hypoxic tumor microenvironment elicits stabilization of HIF-1 $\alpha$ and subsequent induction of VEGF expression. VEGF increases tumor angiogenesis and vascular networks that supply both nutrients and oxygen to tumor cells, resulting in increases in tumor growth and metastasis $[3,4]$. The VEGF family is comprised of the five VEGF isoforms (VEGF-A, VEGF-B, VEGF-C, VEGF-D, and VEGF-E) and PlGF and binds to three primary receptors [22]. Although VEGFR-1 and VEGFR-2 are expressed mainly in endothelial cells and associated with angiogenesis, they have distinct biological functions. VEGFR-1 has high binding affinity for VEGF-A, VEGF-B, and PlGF, but weak angiogenic activity, as compared with VEGFR-2, suggesting a negative inhibitory role in VEGFR-2-induced angiogenesis [28, 29]. However, VEGFR-2 exhibits low binding affinity to VEGFs, but high activity of angiogenic signaling, indicating that VEGFR-2 is a main receptor driving angiogenesis under physiological and pathological conditions.
A

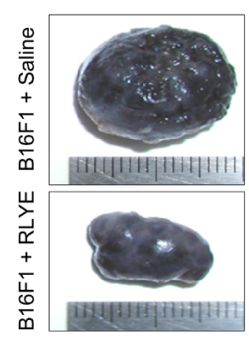

B

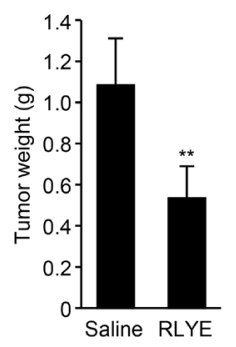

C

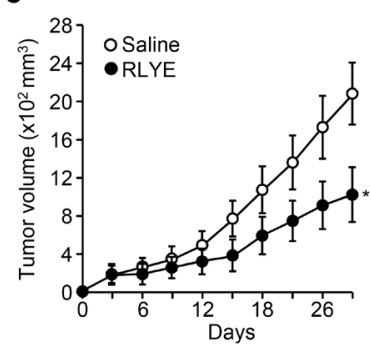

D

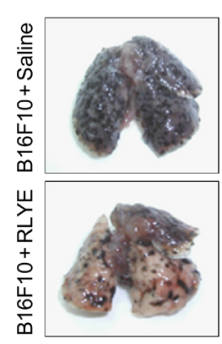

E

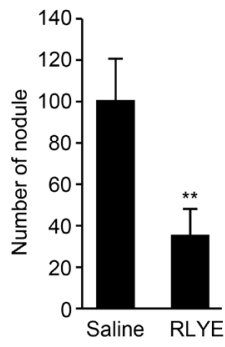

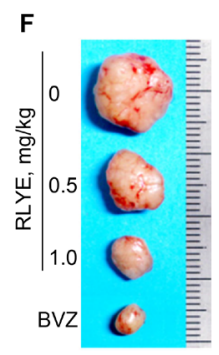
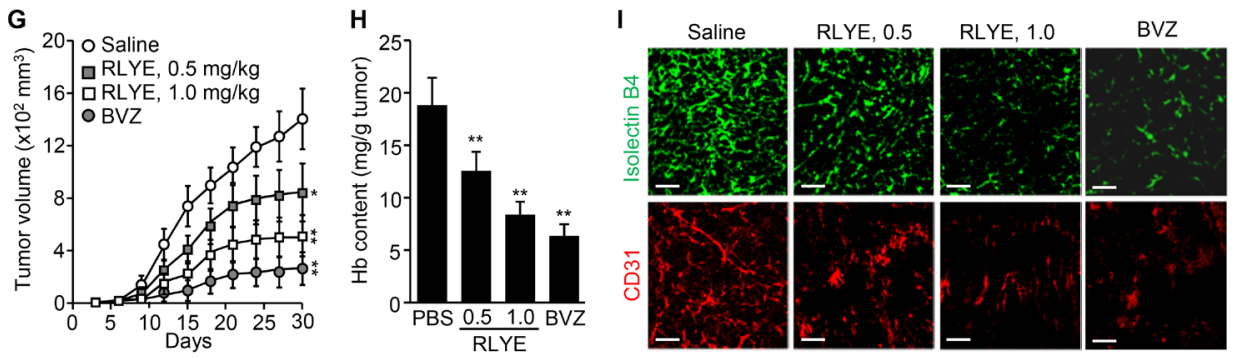

Figure 7: RLYE inhibits tumor growth and metastasis by suppressing tumor angiogenesis. A. Representative tumors isolated from 29-days-old B16F1 tumor-bearing C57BL/6J mice injected i.p. with saline or RLYE (1 mg/kg) every day. B. Tumor weight on day 29 after injection of B16F1 cells $(\mathrm{n}=10$ mice per group). C. Time course inhibition of B16F1 tumor growth by treatment with RLYE ( $\mathrm{n}=10$ mice per group). D. Representative images for metastatic nodules of the lungs isolated from C57BL/6J mice, which were injected i.v. with B16F10 melanoma cells and treated with saline or RLYE for 3 weeks. E. Quantification of the number of lung metastatic nodules. F-I. HCT116 tumor-bearing nude mice treated with saline, RLYE $(0.5 \mathrm{mg} / \mathrm{Kg}$ or $1.0 \mathrm{mg} / \mathrm{Kg})$ every day or bevacizumab (BVZ, $2 \mathrm{mg} / \mathrm{kg})$ twice a week. Representative tumors from 30-day-old HCT116 tumor-bearing mice. (G) Tumor burden was measured every 3 days (n $=8$ mice per group). (H) Functional vascularization was quantified by measuring hemoglobin concentration in HCT116 tumor tissues ( $\mathrm{n}=5$ ). (I) Representative image of tumor sections that were stained with isolectin B4 and an anti-CD31 antibody. Scale bar, $100 \mu \mathrm{m}$. Data are the mean \pm SD. $* P<0.05$ and $* * P<0.01$ versus saline treatment. 
Based on the biological properties of VEGFR-1, the soluble decoy VEGFR-1 aflibercept that has several hundred-fold greater affinity to VEGF-A than bevacizumab has been developed as an antiangiogenic drug for the treatment of colorectal cancer $[30,31]$. Therefore, the VEGF-A/VEGFR-2 system is widely considered a main target of the therapeutic treatment for tumor angiogenesis. Ligation of VEGFR-2 triggers strong proangiogenic signals including p38MAPK/ERK, Src/FAK, and Akt/ eNOS through VEGFR-2 phosphorylation, which promote angiogenesis and VEGFR-2 internalization. Our data show that RLYE blocked the angiogenic signals, angiogenesis, and VEGFR-2 internalization induced by VEGF-A. This suggests that RLYE is an inhibitor of VEGF-A/VEGFR-2 signaling pathways.

Successful blockade of the VEGFR-2 pathway is a potential therapeutic strategy to inhibit tumor angiogenesis and tumor progression. Disruption of VEGFR-2 signaling occurs through three different modes of action by antiangiogenic drugs: specific binding to circulating VEGFs, interference with VEGFs/ VEGFR2 interaction, and inhibition of VEGFR-2-
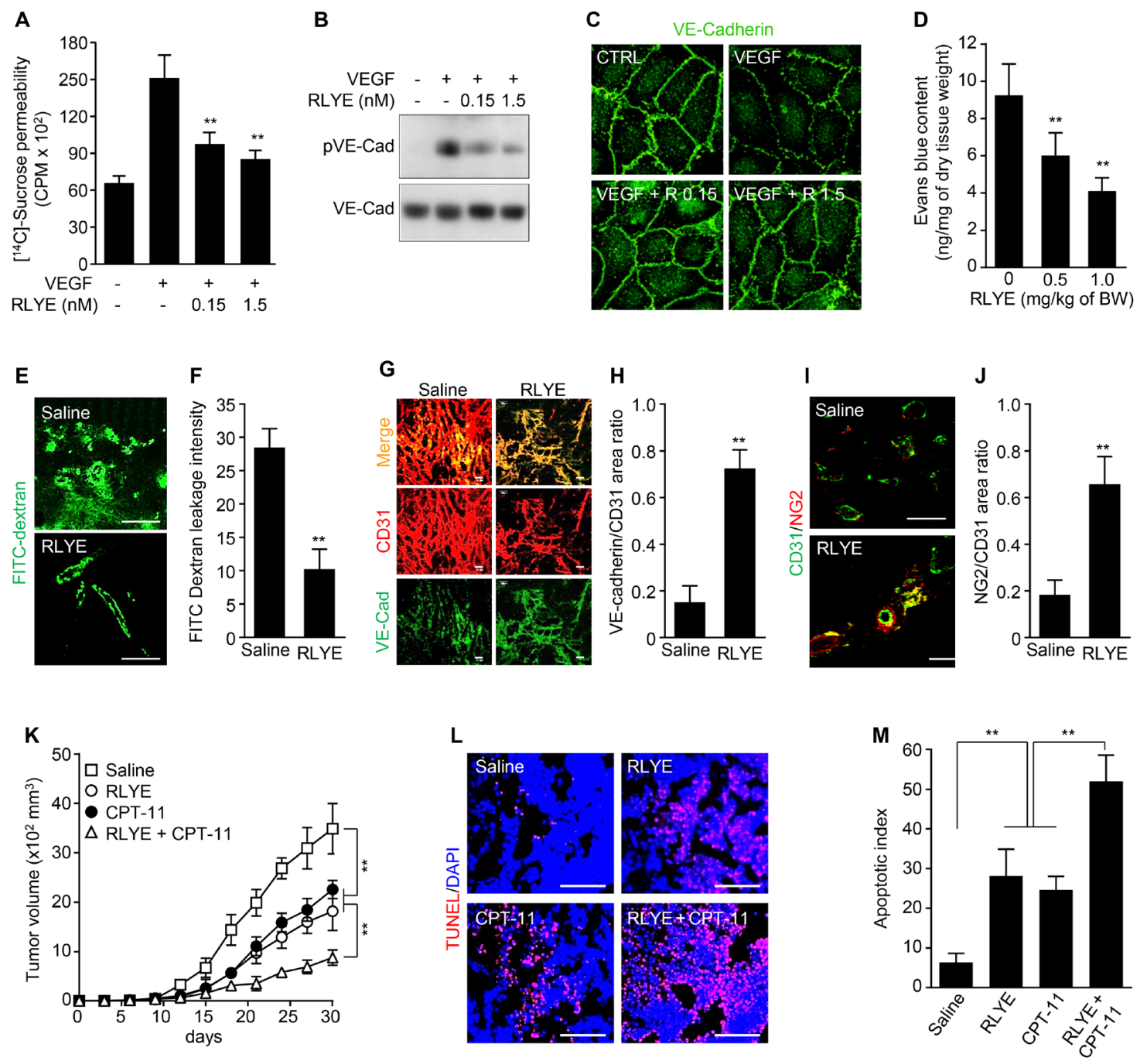

Figure 8: RLYE inhibits vascular leakage and enhances tumor chemosensitivity. A. Endothelial cell permeability was determined by diffusion of $\left[{ }^{14} \mathrm{C}\right]$-sucrose through HUVEC monolayers treated with $20 \mathrm{ng} / \mathrm{ml}$ of VEGF alone or in combination with RLYE $(\mathrm{n}=3)$. B. Phosphorylation of VE-cadherin was determined in cell lysates of HUVECs treated with $20 \mathrm{ng} / \mathrm{ml}$ of VEGF alone or in combination with RLYE. C. Immunostaining of VE-cadherin in endothelial monolayer was determined by confocal microscopy. DJ. HCT116 tumor-bearing mice ( $\mathrm{n}=5$ per group) were injected with saline or RLYE $(0.5 \mathrm{mg} / \mathrm{kg})$ for 12 days. Tumor vascular leakage was determined by the Evans blue method (E and F) or FITC-dextran image assay $(\mathrm{G}$ and $\mathrm{H})$. $(\mathrm{G})$ Immunofluorescence staining of the tumor sections $(\mathrm{n}=5)$ for $\mathrm{CD} 31$ and VE-cadherin, and $(\mathrm{H})$ ratio of VE-cadherin to CD31 was quantified using computer-aided confocal microscopy. (I) Immunofluorescence staining of the tumor sections $(\mathrm{n}=5)$ for CD31 and NG2, and (J) NG2-positive vessels were quantified. K-M. HCT116 tumor-bearing mice ( $\mathrm{n}=7$ per group) were i.p. injected with RLYE $(0.5 \mathrm{mg} / \mathrm{kg} / \mathrm{day})$ alone or in combination with irinotecan (CPT-11, $17 \mathrm{mg} / \mathrm{kg}$ every $5^{\text {th }}$ day). (K) Tumor volumes were measured every 3 days. ( $\mathrm{L}$ and $\left.\mathrm{M}\right)$ Apoptotic cells in tumor tissues were determined and quantified by TUNEL staining. Scale bar, $100 \mu \mathrm{m}$ in all images. ${ }^{* *} P<0.001$ (Student's $t$-test except survival curve data). 
tyrosine kinase [32]. Although several VEGFR-2tyrosine kinase inhibitors have been clinically used, there are some therapeutic limitations, such as development of resistance, lack of tumor response in the general population, and low specificity [13, 33]. Humanized anti-VEGF antibodies including bevacizumab have been integrated into the treatment of patients with different types of cancers. However, recent studies reported that cancer patients with VEGF gene polymorphisms do not respond very well to bevacizumab, and the development of bevacizumab-resistant tumors has become more common [34, 35]. Therefore, other therapeutic approaches including the use of humanized antiVEGFR-2 antibody ramucirumab to block VEGFR-2 have been more attractive to inhibit tumor angiogenesis $[36,37]$. Similarly, our data demonstrate that the tetrapeptide RLYE inhibits VEGF-A-induced tumor angiogenesis by directly binding to VEGFR-2.

RLYE has been shown to inhibit the angiogenic signal cascades in HUVECs stimulated with VEGF-A at a maximum inhibitory molar ratio of 11:1 of RLYE to monomeric VEGF [19], which is different from the approximately 1:1 molar ratio of bevacizumab [38]. This suggests that the peptide does not directly bind to VEGF-A, which is different from the mode of action of bevacizumab. However, our results show that RLYE inhibits the VEGF-A-induced signal pathway by interfering with specific binding of VEGF-A to VEGFR-2. This evidence was further confirmed by the findings that RLYE inhibited in vitro angiogenesis in HUVECs stimulated with VEGF-A, but not with VEGFR-1-specific ligands (PlGF and VEGF-B), and that the peptide did not inhibit VEGF-A-induced proliferation and migration of MM cell lines that expressed only VEGFR-1. These results suggest that RLYE inhibits the VEGF-A/VEGFR-2 pathway, but not the VEFG-A/VEGFR-1 system. This is further supported by biochemical and immunochemical experiments using pull-down assay, FACS, and SPR analysis. Interestingly, our modeling study predicted that this peptide bound to VEGFR-2 at the same site that interacts with VEGF-A [26, 39-41]. These results suggest that RLYE inhibits angiogenic activity of VEGF-A, a major isoform of VEGF family, by binding to VEGFR-2 and subsequently blocking VEGF-A/VEGFR-2 interaction.

Our previous study showed that RLYE has potent antiangiogenic activity with $\mathrm{IC}_{50}$ of $0.06-0.08 \mathrm{nM}$ against VEGF-A [19]. This activity is more potent than those of clinically used antiangiogenic cancer drugs including bevacizumab $\left(\mathrm{IC}_{50}=0.15 \mathrm{nM}\right.$ for VEGF-A), ramucirumab $\left(\mathrm{IC}_{50}=1-2 \mathrm{nM}\right.$ for VEGFR-2), and the tyrosine receptor kinase inhibitor sunitinib $\left(\mathrm{IC}_{50}=80\right.$ $\mathrm{nM}$ for VEGFR-2) in endothelial cell culture conditions $[36,38,42]$. However, we found the antiangiogenic and antitumor activities of RLYE were relatively little lower than those of bevacizumab in a xenograft mouse model.
This unexpected results may be due to a short half-life (1.2 h) of RLYE in blood, compared with its half-life of $>18 \mathrm{~h}$ in $10 \%$ heat-inactivated FBS-supplemented M199 media (unpublished data) and a half-life (12-22 days) of bevacizumab in vivo [43]. These results support that RLYE effectively inhibits tumor progression likely by blocking tumor angiogenesis, although it has a short halflife in vivo. We are now developing stable peptides with a long half-life in vivo, based on amino acid sequence of RLYE, which are used to effectively inhibit VEGFR-2 function in vascular endothelial cells and thereby inhibit tumor angiogenesis, upon which solid tumors depend for growth and metastasis.

Blockade of the VEGF-A signaling pathway inhibits tumor angiogenesis and transiently improves tumor vessel normalization and perivascular cell coverage, leading to reduced vessel permeability and increased vascular perfusion in tumors $[9,10]$. Tumor vessel normalization improves delivery of cancer drugs and therapeutic efficacy. The antiangiogenic antibody bevacizumab with the anticancer drug topotecan significantly inhibits tumor growth, compared with each monotherapy, via tumor vessel normalization in a human brain tumor xenograft model [44]. Similarly, in an earlier study, we show that the vascular leakage blocker Sac-1004 potentiates cisplatininduced antitumor activity via restoration of vascular normalization in tumor-bearing mice [45]. The present data demonstrated that RLYE inhibits tumor vessel permeability and leakage by restoring endothelial junction formation and pericyte coverage, thereby potentiating irinotecan-mediated tumor cell apoptosis and tumor growth inhibition in the tumor-bearing mouse model. Thus, RLYE reduces tumor vessel abnormality and permeability, resulting in enhanced delivery and efficacy of chemotherapeutic agents.

In conclusion, the present study supported the role of RLYE in the prevention of tumor progression and metastasis by selectively inhibiting functional neovessel formation within rapidly growing solid tumors in a mouse model. RLYE also potentiate antitumor activity of cytotoxic anticancer drugs by improving tumor vessel normalization via reduction of vascular permeability and leakage. Moreover, its specific inhibitory effect on the VEGFR-2-mediated signaling pathway could be targeted for the development of pharmaceutical agents that inhibit tumor angiogenesis and tumor blood vessel leakage. This proof of concept study provides the rationale for further investigation of RLYE as an antitumor agent, antiangiogenic drug or vascular leakage blocker in clinically advanced or metastatic solid tumors.

\section{MATERIALS AND METHODS}

\section{Materials}

Cell culture media and supplements were purchased from Invitrogen Life Technologies (Carlsbad, CA). 
Fetal bovine serum (FBS) was obtained from HyClone Laboratories (Logan, UT), and human bFGF and S1P were from Upstate Biotechnology (Lake Placid, NY). Human recombinant proteins including VEGF-A ${ }_{165}$, VEGF-B, EGF, PIGF, and VEGF receptor-2 (rhVEGFR-2) were obtained from R\&D Systems (Minneapolis, MN). RLYE, fluorescein isothiocynate (FITC)-conjugated RLYE, and biotin-labeled RLYE were purchased from Peptron (Daejeon, South Korea). All peptides were dissolved in phosphate-buffered saline (PBS) or saline at a concentration of $15 \mathrm{mM}$ as a stock solution. Antibodies for phospho-ERK (Thr-202/Tyr-204), phospho-Akt (Ser473), phospho-p38 (Thr-180/Tyr-182), phospho-Src (Tyr-416), phosphor-VEGFR-2 (Tyr-1175), phosphoFAK (Tyr-925), ERK, FAK, VEGFR-2, and Akt were obtained from Cell Signaling Technology (Beverly, MA). Antibodies for phospho-eNOS (Ser-1177) and eNOS were purchased from BD Transduction Laboratories (San Diego, CA). Antibodies for VEGFR-1 and p38 were purchased from Santa Cruz Biotechnology (Santa Cruz, CA). Bevacizumab was purchased from Roche (Basel, Switzerland). Thermanox disc was purchased from Nalge Nunc International (Naperville, IL).

\section{Cell culture}

Mouse melanoma B16F1 and B16F10 cells and human HCT116 colon cancer cells were obtained from American Type Culture Collection (Manassas, VA) and cultured in RPMI medium supplemented with 10\% FBS, $1 \mathrm{mM}$ sodium pyruvate, $10 \mathrm{mM}$ 4-(2-hydroxyethyl)-1piperazineethanesulfonic acid, and $100 \mathrm{U} / \mathrm{ml}$ penicillinstreptomycin in a humidified atmosphere of $5 \% \mathrm{CO}_{2}$ at $37^{\circ} \mathrm{C}$. Human umbilical vein endothelial cells (HUVECs) were maintained and cultured in M199 as described previously [19], and only passages 2-7 were used for all experiments. Human multiple myeloma IM-9 and RPMI 8226 cells were obtained from Korean Cell Line Bank (Seoul, Korea). The cells were cultured in RPMI-1640 medium in a humidified $\mathrm{CO}_{2}$ incubator. Cell viability or cytotoxicity was evaluated by 3-[4,5-cimethylthiazol2-yl]-2,5-diphenyl tetrazolium bromide (MTT, SigmaAldrich) assay.

\section{Animals}

Seven-week-old male C57BL/6J or athymic nude mice and Sprague-Dawley rats were purchased from OrientBio (Seongnam, South Korea) and maintained on a standard (normal) chow diet ad libitum in a laminar airflow cabinet under specific pathogen-free conditions. Animal experiments were performed in accordance with the guidelines of the Institutional Animal Care and Use Ethics Committee of Kangwon National University. Moreover, this investigation conformed to the Guide for the Care and Use of Laboratory Animals published by the United States National Institutes of Health (NIH Publication, 8th Edition, 2011).

\section{In vitro angiogenesis assay}

Angiogenic activity was determined by measurements of cell proliferation, migration, and tube formation as described previously [19]. HUVECs were pretreated with RLYE $(0.15 \mathrm{nM})$ for $30 \mathrm{~min}$ and stimulated with several proangiogenic factors including VEGF-A (10 ng/ml), VEGF-B (20 ng/ml), bFGF (10 $\mathrm{ng} / \mathrm{ml}$ ), EGF (20 ng/ml), PlGF (20 ng/ml), and S1P (1 nM). Cell proliferation was determined by $\left[{ }^{3} \mathrm{H}\right]-$ thymidine incorporation assay. Chemotactic migration was analyzed using Transwell plates with $6.5-\mathrm{mm}$ diameter polycarbonate filters ( $8 \mu \mathrm{m}$ pore size). Tube-like structure formation was determined on a layer of growth factor-reduced Matrigel by an inverted phase-contrast microscope $(\times 40)$ and quantified using the Image-Pro Plus version 4.5 (Media Cybernetics, San Diego, CA).

\section{Ex vivo and in vivo angiogenesis assay}

Aortic ring sprouting assay was performed by a modified method based on a previous report [46]. Sprague-Dawley rats (6-week-old, male) and C57BL/6J mice (7-week-old, male) were anesthetized with inhaled halothane (5\%) and then humanely sacrificed. Rat dorsal and mouse thoracic aortas were isolated and carefully cut into 1-mm rings. The aortic rings were placed in the 48well plates pre-coated with $120 \mu \mathrm{l}$ of Matrigel, sealed in place with an overlay of $50 \mu \mathrm{l}$ of Matrigel, and incubated with RLYE $(0.3 \mathrm{nM})$ or VEGF $(20 \mathrm{ng} / \mathrm{ml})$ in a final volume of $200 \mu \mathrm{l}$ of serum-free medium. On day 6 , newly formed vessels were fixed and microvessel outgrowth was photographed under a phase contrast microscope, and angiogenesis was quantified with Image $\mathrm{J}$ software (NIH; http://rsb.info.nih.gov/ij). For chick chorioallantoic membrane (CAM) assay, fertilized chick embryos were incubated for 3 days and then windowed as described previously [46]. Briefly, a window approximately $3 \mathrm{~cm}$ in diameter was formed by removing the shell and inner shell membrane from the air space site and then the exposed area was sealed with cellophane tape. The eggs were returned to the incubator at $37^{\circ} \mathrm{C}$ (humidity 55-60\%) and incubated with the window upright for 3 days. On day 10 , Thermanox discs containing $10 \mu \mathrm{l}$ of salt-free solution containing RLYE (0.75 nM) alone or plus VEGF (50 ng/ $\mathrm{ml}$ ) were loaded onto the CAM of 10-day-old embryos. After $72 \mathrm{~h}$ incubation, the area around the loaded disk was photographed with a Nikon digital camera and the number of newly formed vessels was counted inside the disc area. Neovascularization was determined by intravital fluorescence microscopy as described previously [46]. C57BL/6Jmice were anesthetized by inhalation of $1.5 \%$ isoflurane and $\mathrm{O}_{2}-\mathrm{N}_{2} \mathrm{O}$ using a Surgivet vaporizer 
(Waukesha, WI), and titanium-based imaging windows were surgically implanted between the skin and abdominal wall of mice. Growth factor-reduced Matrigel $(100 \mu \mathrm{l})$ containing RLYE (1.5 nM) or VEGF (100 ng) was applied to the inner space of the window, which was surgically implanted between the skin and abdominal wall of mice. After 4 days, neovascularization was recorded by a Zeiss Axiovert 200M microscope (Carl Zeiss, Jena, Germany) after intravenous injection of $50 \mu \mathrm{l}$ of $25 \mathrm{mg} / \mathrm{ml}$ FITClabeled dextran (MW, $250 \mathrm{kDa}$ ) via the tail vein. Vascular length density was calculated as the length of FITClabeled dextran-perfused blood vessels per observation area $\left(\mathrm{mm} / \mathrm{mm}^{2}\right)$.

\section{Western blot analysis}

Whole cell lysates were prepared using RIPA buffer. To prepare the membrane/cytosolic $(\mathrm{M} / \mathrm{C})$ and nuclear $(\mathrm{N})$ fractions, cells were lysed into buffer A (10 mM HEPES, $\mathrm{pH} 7.9,0.1 \mathrm{mM}$ EDTA, $10 \mathrm{mM} \mathrm{KCl}, 0.1 \mathrm{mM}$ EGTA and $0.1 \%$ Nonidet P-40) and centrifuged at 19,000 x $g$ for 5 min. The supernatant was used as an $M / C$ fraction, and the pellet was resuspended in buffer B (20 mM HEPES, $\mathrm{pH} 7.9,0.4 \mathrm{M} \mathrm{NaCl}, 1 \mathrm{mM}$ EDTA and $0.1 \mathrm{mM}$ EGTA) and lysed by three cycles of freezing and thawing. After centrifugation at 19,000 $\mathrm{x} g$ for $5 \mathrm{~min}$, the supernatant was isolated and used as a nuclear faction. Cell fractions (50 $\mu \mathrm{g}$ protein) were separated by SDS-PAGE and transferred to polyvinylidene difluoride membranes. The membranes were incubated with antibodies against target proteins for $2 \mathrm{~h}$. After washing twice, the membranes were incubated with a horseradish peroxidase-conjugated secondary antibody, and protein levels were detected by an enhanced chemiluminescence system as described previously [46].

\section{Nitric oxide (NO) measurement}

Intracellular NO levels were measured in situ using DAF-FM diacetate according to the manufacturer's instructions. HUVECs were pretreated with $0.15 \mathrm{nM}$ peptide and stimulated with $10 \mathrm{ng} / \mathrm{ml} \mathrm{VEGF}$ for $4 \mathrm{~h}$. Cells were incubated with $5 \mu \mathrm{M}$ (final concentration) 4-amino5-methylamino-2',7'-difluorofluorescein (DAF-FM) diacetate for $30 \mathrm{~min}$ in a $\mathrm{CO}_{2}$ incubator. Intracellular $\mathrm{NO}$ levels were determined using a confocal laser microscope as described previously [19].

\section{Fluorescence-activated cell sorting (FACS) analysis}

HUVECs cultured for $24 \mathrm{~h}$ after plating in $60 \mathrm{~mm}-$ culture dishes. Cells from subconfluent cultures were gently detached from wells with PBS containing $5 \mathrm{mM}$ EDTA, washed three times with PBS, and resuspended in PBS containing $2 \% \mathrm{FBS} / 0.1 \%$ bovine serum albumin. Thereafter, they were incubated with FITC-conjugated RLYE (15 nM) before or after treatment with VEGF (100 $\mathrm{ng} / \mathrm{ml}$ ) for $30 \mathrm{~min}$ on ice, fixed in $2 \%$ paraformaldehyde, and analyzed by flow cytometry in a fluorescenceactivated cell sorter (FACSCalibur, Becton Dickinson, Franklin Lakes, NJ).

\section{Pull-down assay of VEGFR using biotin-labeled RLYE}

HUVECs were incubated with were biotinylated RLYE $(0.15$ or $1.5 \mathrm{nM})$ for $1 \mathrm{~h}$, and the unbound peptide was washed away. Cells were solubilized in pull-down buffer (50 mM Tris- $\mathrm{HCl}$, pH 8.0, with $150 \mathrm{mM}$ sodium chloride, $1.0 \%$ NP-40, $0.5 \%$ sodium deoxycholate and $0.1 \%$ SDS $)$. Cell lysates (500 $\mu$ g protein) were incubated with streptavidin-agarose beads $(20 \mu \mathrm{l})$ at $4^{\circ} \mathrm{C}$ for $1 \mathrm{~h}$. RLYE-bound proteins were isolated form cell lysates by centrifugation, and the precipitated beads were boiled for $10 \mathrm{~min}$. Proteins bound to the beads were separated by SDS-PAGE and probed by immunoblotting with an antibody against VEGFR-2 or VEGFR-1.

\section{Animal models of mouse melanoma and human colon cancer}

C57BL/6J and nude mice were challenged subcutaneously (s.c.) in the left flank with $2 \times 10^{6}$ B16F1 mouse melanoma cells and $1 \times 10^{7}$ HCT116 human colon carcinoma cells in a volume of $100 \mu \mathrm{l}$, respectively. After the tumor volume became at least 50-70 $\mathrm{mm}^{3}$, which occurred within 7 days, the mice were injected intraperitoneally (i.p.) with saline, RLYE $(0.5$ or $1.0 \mathrm{mg} / \mathrm{kg})$ every day or bevacizumab $(2 \mathrm{mg} /$ $\mathrm{kg})$ twice a week from 6 to 30 days after tumor cell injection. Some mice were treated with RLYE $(0.5 \mathrm{mg} /$ $\mathrm{kg} /$ day) or in combination with irinotecan (CPT-11, 17 $\mathrm{mg} / \mathrm{kg}$ ) every fifth day. Tumor size was measured in two dimensions using calipers. Tumor volume $\left(\mathrm{mm}^{3}\right)$ was calculated using the formula: width $^{2} \mathrm{x}$ length $\mathrm{x}$ 0.52 [16]. Tumor tissue was homogenized with PBS and centrifuged $(12,000 \times \mathrm{g}, 5 \mathrm{~min})$. The supernatant with hemoglobin was taken for analysis with Drabkin's reagent (Sigma-Aldrich). The level of hemoglobin derivative cyanmethemoglobin was measured by spectrophotometry, and the amounts of hemoglobin were calculated per $1 \mathrm{~g}$ of tumor.

\section{Experimental tumor metastasis model}

C57BL/6J mice were injected with $1 \times 10^{5} \mathrm{~B} 16 \mathrm{~F} 10$ mouse melanoma cells via the lateral tail vein. Mice were injected i.p. every day with $1 \mathrm{mg} / \mathrm{kg}$ RLYE in a volume of $100 \mu \mathrm{l}$ for 3 weeks. The lungs were excised, rinsed in Dulbecco's PBS, and fixed overnight in 4\% paraformaldehyde solution. The number of metastatic nodules present over the entire surface of the lungs was counted under a dissecting microscope. 


\section{Endothelial cell and tumor vessel permeability}

HUVECs were plated on Transwell plates and grown to formation of a confluent monolayer. Cells were incubated with M199 containing 1\% FBS for $3 \mathrm{~h}$ and treated with various concentrations of RLYE for 30 min, followed by stimulation with $20 \mathrm{ng} / \mathrm{ml}$ of VEGF for $1 \mathrm{~h}$. Fifty $\mu \mathrm{l}$ of $\left[{ }^{14} \mathrm{C}\right]$-sucrose $(0.8 \mu \mathrm{Ci} / \mathrm{ml}$; Amersham Pharmacia) was added to the upper compartment. After $30 \mathrm{~min}$, endothelial cell permeability was determined by measuring the amount of radioactivity that diffused into the lower compartment using a liquid scintillation counter. Tumor vessel permeability was assessed by Evans blue dye and FITC-dextran as previously described [45]. Evans blue $(50 \mathrm{mg} / \mathrm{kg})$ was injected intravenously into HCT116 tumor-bearing mice treated with saline or RLYE $(0.5 \mathrm{mg} / \mathrm{kg} /$ day $)$ for 12 days, and tumors were excised $30 \mathrm{~min}$ later. They were dried at $60^{\circ} \mathrm{C}$ for $16 \mathrm{~h}$ and then dye was extracted with $1 \mathrm{ml}$ formamide at $55^{\circ} \mathrm{C}$ for $16 \mathrm{~h}$. The amount of extravasated Evans blue was determined by measuring absorbance at $620 \mathrm{~nm}$ using its standard solution by spectrophotometry. Vascular leakage visualization with FITC-dextran was achieved by an intravenous injection of $3 \mathrm{mg}$ /mouse FITC-dextran (40-kDa; Sigma Aldrich) $10 \mathrm{~min}$ before capture of tumor. Tumors were then fixed briefly in $4 \%$ paraformaldehyde and cryosections were made to observe vascular leakage under fluorescence microscope.

\section{Surface plasmon resonance (SPR) assay}

Binding kinetics and affinities of RLYE to rhVEGFR-2 were assessed using a BIAcore AB (Uppsala, Sweden). Carboxymethylated dextran biosensor chip (CM5, BIAcore $\mathrm{AB}$ ) were activated with 1-ethyl-3-(3-dimethylaminopropyl and $\mathrm{N}$ hydroxysuccinimide according to the supplier's instructions. Successful immobilization of rhVEGFR-2 was achieved by injecting rhVEGFR-2 ( $1 \mathrm{ng} / \mu \mathrm{l}$ in HBS-EP buffer containing $10 \mathrm{mM}$ Hepes, $150 \mathrm{mM}$ $\mathrm{NaCl}, 3 \mathrm{mM}$ EDTA, and $0.005 \%$ Tween-20) onto the activated CM5 chip. To obtain kinetic data, different concentrations of RLYE in HBS-EP buffer were injected over the sensor chip at a flow rate of $25 \mu \mathrm{l} / \mathrm{min}$, and the association and dissociation behavior were compared. Peptide binding was measured in response units. At the end of each sample injection $(120 \mathrm{sec})$, HBS-EP buffer was passed over the sensor surface to monitor the dissociation phase. The equilibrium dissociation constant (Kd) was derived by a steady state binding model.

\section{Immunostaining analysis}

For immunocytochemistry, HUVECs were grown to confluence on glass coverslips coated with $2 \%$ gelatin and treated with or without VEGF-A $(10 \mathrm{ng} / \mathrm{ml})$ for 30 min, followed by incubation with FITC-RLYE (100 ng/ $\mathrm{ml}$ ). Cells were fixed in $3.7 \%$ formaldehyde for $30 \mathrm{~min}$ and permeabilized with $0.2 \%$ Triton X-100 in PBS, then incubated with blocking solution of PBS containing 3\% normal goat serum and $0.05 \%$ Tween-20. Cells were labeled with antibodies against human VE-cadherin (Santa Cruz) and human CD31 (PECAM-1, Santa Cruz). Tumor sections $(30 \mu \mathrm{m})$ were stained as previously described [45] by incubating with one of the following antibodies: rat anti-CD31, (Pharmingen), goat anti-VE-cadherin (Santa Cruze), and rabbit anti-NG2 (Millipore) for $2 \mathrm{~h}$ at room temperature, rinsed in PBS, and incubated with Alexa Fluor-, FITC- or TRITC-conjugated secondary antibody for 60 or $90 \mathrm{~min}$ at room temperature. Some tumor sections were also incubated with FITC-isolectin B4 (5 $\mu \mathrm{g} / \mathrm{ml}$; Vector Laboratories, Burlingame, CA) for $1 \mathrm{~h}$. The sections were mounted with Permount solution after washing three times with PBS. Images were photographed and analyzed using a confocal fluorescence microscope. Nuclear staining was performed with 4', 6-diamidino-2phenylindole (DAPI, $1 \mathrm{ng} / \mathrm{ml}$ ), and apoptotic cells were detected using a terminal deoxynucleotidyl transferase dUTP nick end labeling (TUNEL) kit (Roche, Korea).

\section{Docking simulations}

Coordinates of RLYE peptide were generated by Chimera [47]. We performed blind docking of RLYE to VEGFR-2 (PDB ID 2X1W), which was extracted from the structure of the VEGF/VEGFR-2 complex [26]. Using Autodock 4.2 [48], a large grid box of $0.15 \AA$ spacing was set up to encompass the whole VEGFR-2 molecule. Number of energy evaluations was increased to 50 million to account for the large number of rotatable bonds in the RLYE peptide. We performed 1000 blind docking simulations with a Lamarckian genetic algorithm. Chimera software was used for graphic presentation [47].

\section{Statistical analysis}

Quantitative data are expressed as mean \pm standard deviation (SD) of at least three separate experiments. Statistical significance was determined using the unpaired Student's $t$ test or ANOVA, depending on the number of experimental groups analyzed. Significance was established at a $p$ value $<0.05$.

\section{ACKNOWLEDGMENTS}

This work was supported by the National Research Foundation of Korea (NRF) Grant funded by the Korea Government (2013M3A9B6046563 and 2015M3A9E6028949).

\section{CONFLICTS OF INTEREST}

The authors declare no conflicts of interest. 


\section{REFERENCES}

1. Semenza G. Signal transduction to hypoxia-inducible factor 1. Biochem Pharmacol. 2002; 64:993-998.

2. Semenza GL. Regulation of cancer metabolism by hypoxiainducible factor 1. Semin Cancer Biol. 2009; 19:12-16.

3. Folkman J. Angiogenesis: an organizing principle for drug discovery? Nat Rev Drug Discov. 2007; 6:273-286.

4. Papetti M, Herman IM. Mechanisms of normal and tumorderived angiogenesis. Am J Physiol Cell Physiol. 2002; 282:947-970.

5. Youssoufian H, Hicklin DJ, Rowinsky EK. Review: monoclonal antibodies to the vascular endothelial growth factor receptor-2 in cancer therapy. Clin Cancer Res. 2007; 13:5544-5548.

6. Zhang J, Yang PL, Gray NS. Targeting cancer with small molecule kinase inhibitors. Nat Rev Cancer. 2009; 9:28-39.

7. Bono F, De Smet F, Herbert C, De Bock K, Georgiadou M, Fons P, Tjwa M, Alcouffe C, Ny A, Bianciotto M, Jonckx B, Murakami M, Lanahan AA, et al. Inhibition of tumor angiogenesis and growth by a small-molecule multi-FGF receptor blocker with allosteric properties. Cancer Cell. 2013; 23:477-488.

8. McIntyre A, Harris AL. Metabolic and hypoxic adaptation to anti-angiogenic therapy: a target for induced essentiality. EMBO Mol Med. 2015; 7:368-379.

9. Jain RK. Normalization of tumor vasculature: an emerging concept in antiangiogenic therapy. Science. 2005; 307:58-62.

10. Weis SM, Cheresh DA. Tumor angiogenesis: molecular pathways and therapeutic targets. Nat Med. 2011; 17:1359-1370.

11. Ranpura V, Hapani S, Wu S. Treatment-related mortality with bevacizumabin cancer patients: a meta-analysis. JAMA. 2011; 305:487-494.

12. Cook KM, Figg WD. Angiogenesis inhibitors: current strategies and future prospects. CA Cancer J Clin. 2010; 60:222-243

13. Verheul HM, Pinedo HM. Possible molecular mechanisms involved in the toxicity of angiogenesis inhibition. Nat Rev Cancer. 2007; 7:475-485.

14. Wang J, Wang Z, Zhao Y. Incidence and risk of hypertension with ramucirumab in cancer patients: a meta-analysis of published studies. Clin Drug Invest. 2015; 356:221-228.

15. Sashegyi A, Lin Y, Ferry D, Melemed A. Comment on: Incidence and Risk of Hypertension with Ramucirumab in Cancer Patients: A Meta-Analysis of Published Studies. Clin Drug Invest. 2015; 35:405.

16. O'Reilly MS, Holmgren L, Shing Y, Chen C, Rosenthal RA, Moses M, Lane WS, Cao Y, Sage EH and Folkman J. Angiostatin: a novel angiogenesis inhibitor that mediates the suppression of metastases by a Lewis lung carcinoma. Cell. 1994; 79:315-328.
17. Cao Y, Chen A, An SSA, Ji RW, Davidson D, Llinas M. Kringle 5 of plasminogen is a novel inhibitor of endothelial cell growth. J Biol Chem. 1997; 272:22924-22928.

18. Sheppard GS, Kawai M, Craig RA, Davidson DJ, Majest SM, Bell RL, Henkin J. Lysyl 4-aminobenzoic acid derivatives as potent small molecule mimetics of plasminogen kringle 5. Bioorg Med Chem Lett. 2004; 14:965-966.

19. Baek YY, Lee DK, So JH, Kim CH, Jeoung D, Lee H, Choe J, Won MH, Ha KS, Kwon YG, Kim YM. The tetrapeptide Arg-Leu-Tyr-Glu inhibits VEGF-induced angiogenesis. Biochem Biophys Res Commun. 2015; 463:532-527.

20. Papapetropoulos A, García-Cardeña G, Madri JA, Sessa WC. Nitric oxide production contributes to the angiogenic properties of vascular endothelial growth factor in human endothelial cells. J Clin Invest. 1997; 100:3131-3139.

21. Lee OH, Kim YM, Lee YM, Moon EJ, Lee DJ, Kim JH, Kim KW, Kwon YG. Sphingosine 1-phosphate induces angiogenesis: its angiogenic action and signaling mechanism in human umbilical vein endothelial cells. Biochem Biophys Res Commun. 1999; 264:743-750.

22. Hicklin DJ, Ellis LM. Role of the vascular endothelial growth factor pathway in tumor growth and angiogenesis. J Clin Oncol. 2005; 23:1011-1127.

23. Podar K, Tai YT, Davies FE, Lentzsch S, Sattler M, Hideshima T, Lin BK, Gupta D, Shima Y, Chauhan D, Mitsiades C, Raje N, Richardson P, Anderson KC. Vascular endothelial growth factor triggers signaling cascades mediating multiple myeloma cell growth and migration. Blood. 2001; 98:428-435.

24. Podar K, Tai YT, Lin BK, Narsimhan RP, Sattler M, Kijima T, Salgia R, Gupta D, Chauhan D, Anderson KC. Vascular endothelial growth factor-induced migration of multiple myeloma cells is associated with beta 1 integrinand phosphatidylinositol 3-kinase-dependent PKC alpha activation. J Biol Chem. 2002; 277:7875-7881.

25. Santos SC, Miguel C, Domingues I, Calado A, Zhu Z, Wu Y, Dias S. VEGF and VEGFR-2 (KDR) internalization is required for endothelial recovery during wound healing. Exp Cell Res. 2007; 313:1561-1574.

26. Leppänen VM, Prota AE, Jeltsch M, Anisimov A, Kalkkinen N, Strandin T, Lankinen H, Goldman A, Ballmer-Hofer K, Alitalo K. Structural determinants of growth factor binding and specificity by VEGF receptor 2. Proc Natl Acad Sci U S A. 2010; 107:2425-2430.

27. Min JK, Han KY, Kim EC, Kim YM, Lee SW, Kim OH, Kim KW, Gho YS, Kwon YG. Capsaicin inhibits in vitro and in vivo angiogenesis. Cancer Res. 2004; 64:644-651.

28. Carmeliet P, Moons L, Luttun A, Vincenti V, Compernolle V, De Mol M, Wu Y, Bono F, Devy L, Beck H, Scholz D, Acker T, DiPalma T, et al. Synergism between vascular endothelial growth factor and placental growth factor contributes to angiogenesis and plasma extravasation in pathological conditions. Nat. Med. 2001; 7:575-583. 
29. Kerbel RS. Tumor angiogenesis. N Engl J Med. 2008; 358:2039-2049.

30. Holash J, Davis S, Papadopoulos N, Croll SD, Ho L, Russell M, Boland P, Leidich R, Hylton D, Burova E, Ioffe E, Huang T, Radziejewski C, et al. VEGF-Trap: a VEGF blocker with potent antitumor effects. Proc Natl Acad Sci U S A. 2002; 99:11393-11399.

31. Wachsberger PR, Burd R, Cardi C, Thakur M, Daskalakis C, Holash J, Yancopoulos GD, Dicker AP.VEGF trap in combination with radiotherapy improves tumor control in u87 glioblastoma. Int J Radiat Oncol Biol Phys. 2007; 67:1526-1537.

32. Grothey A, Galanis E. Targeting angiogenesis: progress with anti-VEGF treatment with large molecules. Nat Rev Clin Oncol. 2009; 6:507-518.

33. Arora A, Scholar EM. Role of tyrosine kinase inhibitors in cancer therapy. J Pharmacol Exp Ther. 2005; 315:971-979.

34. Formica V, Palmirotta R, Del Monte G, Savonarola A, Ludovici G, De Marchis ML, Grenga I, Schirru M, Guadagni F, Roselli M. Predictive value of VEGF gene polymorphisms for metastatic colorectal cancer patients receiving firstline treatment including fluorouracil, irinotecan, and bevacizumab. Int J Colorectal Dis. 2011; 26:143-151.

35. Di Stefano AL, Labussiere M, Lombardi G, Eoli M, Bianchessi D, Pasqualetti F, Farina P, Cuzzubbo S, GallegoPerez-Larraya J, Boisselier B, Ducray F, Cheneau C, Moglia A, et al. VEGFA SNP rs2010963 is associated with vascular toxicity in recurrent glioblastomas and longer response to bevacizumab. J Neurooncol. 2015; 121:499-504.

36. Miao HQ, Hu K, Jimenez X, Navarro E, Zhang H, Lu D, Ludwig DL, Balderes P, Zhu Z. Potent neutralization of VEGF biological activities with a fully human antibody Fab fragment directed against VEGF receptor 2. Biochem Biophys Res Commun. 2006; 345:438-445.

37. Clarke JM, Hurwitz HI. Targeted inhibition of VEGF Receptor-2: An update on Ramucirumab. Expert Opin Biol Ther. 2013; 13:1187-1196.

38. Wang Y, Fei D, Vanderlaan M, Song A. Biological activity of bevacizumab, a humanized anti-VEGF antibody in vitro. Angiogenesis. 2004; 7:335-345.

39. Davis-Smyth T, Presta LG, Ferrara N. Mapping the charged residues in the second immunoglobulin-like domain of the vascular endothelial growth factor/placenta growth factor receptor Flt-1 required for binding and structural stability. J Biol Chem. 1998; 273:3216-3222.
40. Fuh G, Li B, Crowley C, Cunningham B, Wells JA. Requirements for binding and signaling of the kinase domain receptor for vascular endothelial growth factor. J Biol Chem. 1998; 273:11197-11204.

41. Ruch C, Skiniotis G, Steinmetz MO, Walz T, BallmerHofer K. Structure of a VEGF-VEGF receptor complex determined by electron microscopy. Nat Struct Mol Biol. 2007; 14:249-250.

42. Sun L, Liang C, Shirazian S, Zhou Y, Miller T, Cui J, Fukuda JY, Chu JY, Nematalla A, Wang X, Chen H, Sistla A, Luu TC, et al. Discovery of 5-[5-fluoro-2-oxo-1,2-dihydroindol(3Z)-ylidenemethyl]-2,4-dimethyl-1H-pyrrole-3-carboxylic acid (2-diethylaminoethyl)amide, a novel tyrosine kinase inhibitor targeting vascular endothelial and platelet-derived growth factor receptor tyrosine kinase. J Med Chem. 2003; 46:1116-1119.

43. McCormack PL, Keam SJ. Bevacizumab: a review of its use in metastatic colorectal cancer. Drugs. 2008; 68:487-506.

44. Dickson PV, Hamner JB, Sims TL, Fraga CH, Ng CY, Rajasekeran S, Hagedorn NL, McCarville MB, Stewart CF, Davidoff AM. Bevacizumab-induced transient remodeling of the vasculature in neuroblastoma xenografts results in improved delivery and efficacy of systemically administered chemotherapy. Clin Cancer Res. 2007; 13:3942-3950.

45. Agrawal V, Maharjan S, Kim K, Kim NJ, Son J, Lee K, Choi HJ, Rho SS, Ahn S, Won MH, Ha SJ, Koh GY, Kim YM, et al. Direct endothelial junction restoration results in significant tumor vascular normalization and metastasis inhibition in mice. Oncotarget. 2014; 5:2761-2777. doi: 10.18632/oncotarget.1942.

46. Na HJ, Hwang JY, Lee KS, Choi YK, Choe J, Kim JY, Moon HE, Kim KW, Koh GY, Lee H, Jeoung D, Won MH, $\mathrm{Ha} \mathrm{KS}$, et al. TRAIL negatively regulates VEGF-induced angiogenesis via caspase-8-mediated enzymatic and nonenzymatic functions. Angiogenesis. 2014; 1:179-194.

47. Pettersen EF, Goddard TD, Huang CC, Couch GS, Greenblatt DM, Meng EC, Ferrin TE. UCSF Chimera--a visualization system for exploratory research and analysis. J Comput Chem. 2004; 25:1605-1612.

48. Morris GM, Huey R, Lindstrom W, Sanner MF, Belew RK, Goodsell DS, Olson AJ. Autodock4 and AutoDockTools4: automated docking with selective receptor flexibility. J Comput Chem. 2009; 16:2785-2791. 